\title{
Corneal Stiffness and Collagen Cross-Linking Proteins in Glaucoma: Potential for Novel Therapeutic Strategy
}

\author{
Najiha Rahman, ${ }^{1}$ Evelyn O'Neill, ${ }^{1}$ Mustapha Irnaten, ${ }^{2}$ Deborah Wallace, ${ }^{2}$ and Colm O'Brien ${ }^{1,2}$
}

\begin{abstract}
Biomechanical properties of the cornea have recently emerged as clinically useful in risk assessment of diagnosing glaucoma and predicting disease progression. Corneal hysteresis $(\mathrm{CH})$ is a dynamic tool, which measures viscoelasticity of the cornea. It represents the overall deformability of the cornea, and reduces significantly with age. Low $\mathrm{CH}$ has also been associated with optic nerve damage and progression of visual field loss in glaucoma. The extracellular matrix (ECM) constituents of the cornea, trabecular meshwork (TM), sclera, and lamina cribrosa (LC) are similar, as they are predominantly made of fibrillar collagen. This suggests that biomechanical changes in the cornea may also reflect optic nerve compliance in glaucomatous optic neuropathy, and in the known increase of TM tissue stiffness in glaucoma. Increased collagen cross-linking contributes to tissue stiffening throughout the body, which is observed in normal aging and occurs at an accelerated rate in systemic conditions such as fibrotic and cardiovascular diseases, cancer, and glaucoma. We reviewed 3 ECM cross-linking proteins that may have a potential role in the disease process of increased tissue stiffness in glaucoma, including lysyl oxidase (LOX)/lysyl oxidase-like 1 (LOXL1), tissue transglutaminase (TG2), and advanced glycation end products. We also report elevated messenger RNA (mRNA) levels of LOX and TG2 in glaucoma LC cells to support our proposed theory that increased levels of cross-linking proteins in glaucoma play a role in LC tissue stiffness. We highlight areas of research that are needed to better understand the role of cross-linking in glaucoma pathogenesis, leading potentially to a novel therapeutic strategy.
\end{abstract}

Keywords: glaucoma, cornea, hysteresis, cross-linking enzymes, stiffness

\section{Introduction}

T he Ocular Hypertension Trial Study (OHTS) identified thinner central corneal thickness (CCT) measurements as a baseline factor that predicted the development of primary open-angle glaucoma (POAG). ${ }^{1}$ Elevated intraocular pressure (IOP) is the only known modifiable risk factor for glaucoma development and progression, and lowering IOP is known to slow progression. ${ }^{2-5}$ Thinner CCT results in an underestimation of the true IOP measurement. However, inaccuracy of IOP measurements alone cannot fully explain the relationship between CCT and glaucoma risk. We propose that understanding the biomechanical properties of the cornea and their response to pressure would provide a more comprehensive understanding of its role in glaucoma. ${ }^{6}$

Corneal hysteresis $(\mathrm{CH})$ is a biomechanical property of the cornea relating to its viscoelasticity-specifically, the relative ability of the cornea to absorb pressure by bending when pressure is applied. Lower $\mathrm{CH}$ has emerged as a potentially significant factor in the development and progression of glaucoma, and $\mathrm{CH}$ of $<10 \mathrm{mmHg}$ has been found in glaucomatous patients when compared to normal controls. $^{7-13}$ Low $\mathrm{CH}$ indicates a stiffer cornea, which suggests it is unable to disperse the internal force (i.e., stress) created by raised IOP within the anterior segment. This undispersed stress could potentially be transmitted posteriorly to the optic nerve head $(\mathrm{ONH}),{ }^{14}$ contributing to optic nerve cupping and neuronal cell death. Low $\mathrm{CH}$ may also be indicative of globe biomechanical properties and susceptibility to IOP stress. $^{15}$

The cornea consists of 5 layers and the stroma accounts for $90 \%$ of the corneal volume and consists of mostly Type I collagen fibrils ${ }^{16,17}$ in its extracellular matrix (ECM). The $\mathrm{ECM}$ of the cornea is also rich in proteoglycans such as

\footnotetext{
${ }^{1}$ UCD Department of Ophthalmology, Mater Misericordiae University Hospital, Dublin, Ireland.
}

${ }^{2}$ UCD Clinical Research, Catherine Mcauley Centre, Dublin, Ireland. 
keratin sulfate and dermatan sulfate-all of which contribute to the transparency and structural mechanics of the cornea. ${ }^{18}$ Type IV collagen is only found in basement membranes (BM) and acts as a scaffolding protein ${ }^{19}$ to maintain the function of the BM, which includes induction of cell differentiation and facilitation of cell migration. ${ }^{20}$ The presence of Type IV collagen has been observed in the corneal epithelium BM and Descemet's membrane. ${ }^{21,22} \mathrm{~A}$ potential cause of low $\mathrm{CH}$ could be an increase in collagen cross-linking within the cornea, as seen in the normal aging process. $^{23}$

Tissue stiffness can be defined as the degree to which a tissue resists deformation in response to applied stress. The tissue biomechanical property depends largely on the ECM, where its constituents such as elastic fibers, fibrillar collagen, and glycoaminoglycans (GAGs) are regulated to achieve mechanical homeostasis. ${ }^{24}$ Increased collagen crosslinking is observed with increasing age and contributes to the disease process of various systemic conditions, including arteriosclerosis, renal, hepatic, and pulmonary fibrosis, and cancer. $^{25-27}$ Enzymes that cross-link between 2 proteins, normally between collagen and another ECM constituent such as elastin, are regulated to maintain mechanical homeostasis. Altered cross-linking processes result in tissue stiffness.

There are 3 cross-linking proteins potentially associated with glaucoma, which include lysyl oxidase (LOX)/lysyl oxidase-like 1 (LOXL1), tissue transglutaminase (TG2), and advanced glycation end products (AGEs). These proteins have been implicated in the increased stiffness of the eye as a consequence of increased expression in the lamina cribrosa (LC) $)^{28-30}$ or trabecular meshwork (TM) cells. ${ }^{31}$

The aim of this review is to provide an understanding of the biomechanical properties of the cornea and its relevance to glaucoma, coupled with an overview of collagen crosslinking proteins in relationship to glaucoma. We will also discuss future potential therapeutic strategies in reducing the risk of developing and progression of this blinding disease.

\section{Literature search strategy}

As preparation for writing this review article, we performed a literature search to identify all of the relevant scientific articles. We used the PubMed database as our searching tool and entered keywords, including aging, glaucoma, ocular stiffness, $\mathrm{CH}$, collagen cross-linking proteins, optic nerve stiffness, and ECM. We also made use of the relevant studies referenced in selected articles that were not identified from our initial search process. There was no constraint on publication date and we included articles that are published in English language only.

\section{CCT and Glaucoma}

The cornea and its significance in glaucoma were first highlighted by the OHTS trial. ${ }^{1,32}$ Goldmann Applanation Tonometry (GAT) was introduced in the 1950s and has become the standard for IOP measurement in clinical practice. The development of GAT and IOP measurement provided a basis for IOP to be recognized as a modifiable risk factor in the development and progression of glaucoma. The key influence of CCT on IOP and glaucoma development was not known for a further 50 years.
Brandt et al. ${ }^{32}$ found that subjects with ocular hypertension $(\mathrm{OHT})$ had thicker corneas than the general population. African American subjects had thinner corneas than white subjects, while thicker CCT was associated with younger age, female gender, and diabetes. Thus, he concluded CCT might influence the accuracy of GAT in the diagnosis, screening, and management of patients with glaucoma and OHT.

Several studies noted the influence of CCT on IOP measurement and suggested it would be ideal to adjust for CCT to attain the "true" IOP. ${ }^{33,34}$ However, there is no consensus on a robust formula for this "correction factor" to eliminate the confounding CCT value in IOP measurement.

\section{CCT as a risk factor for progression of glaucoma}

Gordon et al. ${ }^{1}$ found that participants in the OHTS with a CCT $<555 \mu \mathrm{m}$ had a 3-fold greater risk of developing glaucoma. The Early Manifest Glaucoma Trial (EMGT) found that thinner CCT (1.01-1.55 per $40 \mu \mathrm{m}$ lower) may play a role in predicting progression in those with higher baseline IOP. ${ }^{35}$ Other studies have shown that progression of visual field loss in glaucoma was associated with thinner CCT measurements. ${ }^{35-39}$ Thus, the role of CCT in glaucoma is likely more complex than inaccuracy of IOP measurement, leading to undertreating /overtreating of glaucoma. It is likely that the human cornea and its biomechanical properties rather than just CCT alone influence the risk of development and progression of glaucoma.

\section{Corneal Hysteresis}

$\mathrm{CH}$ is defined as the nature of the cornea's response to an applied force and is dependent on both the elastic and viscous properties. The Reichert Ocular Response Analyzer (ORA; New York, NY) is a simple and noninvasive technique that is commercially available to measure the biomechanical properties of the cornea and $\mathrm{CH}$. As $\mathrm{CH}$ is a measure of the cornea's ability to absorb and dissipate energy, the ORA uses the concept of rapid loading/unloading mechanism on the cornea. Bidirectional applanation by airjet pressure measures the viscoelastic property of the cornea, which is detected by a photodetector (Fig. 1A). ${ }^{40}$ The difference between the rapid loading pressure $(\mathrm{P} 1)$ and rapid unloading pressure $(\mathrm{P} 2)$ in $\mathrm{mmHg}$ is the $\mathrm{CH}$ (Fig. 1B). ${ }^{40}$

Recently, a second commercial instrument has been introduced into clinical practice. The Oculus Corvis ST (Wetzlar, Germany) captures corneal deformation, IOP, and pachymetry measurements using Scheimpflug images to provide a detailed analysis of the biomechanics of the cornea.

\section{$\mathrm{CH}$ and aging}

A recent cross-sectional study within the UK Biobank with 93,345 eligible participants explored the distribution of $\mathrm{CH}$ and its associated factors. ${ }^{41}$ It was found that $\mathrm{CH}$ was significantly associated with age, gender, and ethnicity, all of which are known risk factors for developing glaucoma and should be taken into account when interpreting $\mathrm{CH}$ values. In this large cohort group, lower $\mathrm{CH}$ was significantly associated with higher prevalence of self-reported glaucoma.

There are various studies that precede and support the UK Biobank's findings. $\mathrm{CH}$ in normal controls has been shown to be between 10.2 and $12.6 \mathrm{mmHg},{ }^{42-44}$ with little variation in $\mathrm{CH}$ over a $24-\mathrm{h}$ period. ${ }^{4,45} \mathrm{CH}$ is thought to be heritable, 


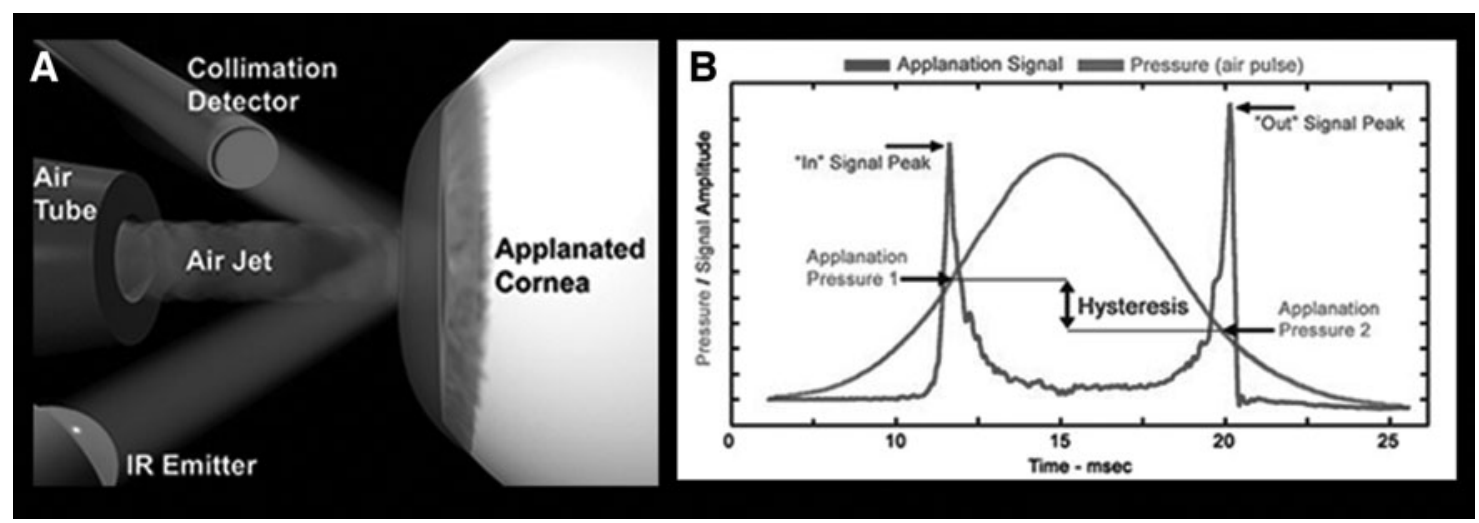

FIG. 1. (A) Bidirectional applanation of the cornea is detected by a photodetector to measure corneal hysteresis in mmHg. ${ }^{40}$ (B) ORA reading measures the inward applanation, P1, and outward applanation of the cornea to regain its normal form, P2. Corneal hysteresis $=\mathrm{P} 1-\mathrm{P} 2 \mathrm{mmHg} .{ }^{40} \mathrm{ORA}$, Ocular Response Analyzer.

with the strongest correlation found among monozygotic twins $^{46}$ and first-degree relatives. ${ }^{47}$ In terms of ethnicity, Detry-Morel et al. compared the $\mathrm{CH}$ values between 30 African with 25 Caucasian normal subjects. They found African normal (non-glaucoma) subjects to have lower $\mathrm{CH}$ $(8.3 \pm 1.7 \mathrm{mmHg}, P<0.001)$ in comparison to Caucasians $(9.2 \pm 1.1 \mathrm{mmHg})^{48}$ of the same age.

$\mathrm{CH}$ decreases with increasing age. ${ }^{13,45,49-51}$ Mean $\mathrm{CH}$ among children has been found to be between 11.78 and $12.5 \mathrm{mmHg} .{ }^{13,49}$ The European Prospective Investigation of Cancer (EPIC)-Norfolk Study ${ }^{50}$ found a mean $\mathrm{CH}$ of $9.35 \mathrm{mmHg}$ in men and $9.74 \mathrm{mmHg}$ in women over 80 years of age. Ortiz et al. ${ }^{51}$ found $\mathrm{CH}$ in those $60-80$ years of age was $10.0 \pm 1.2 \mathrm{mmHg}$ and significantly lower when compared to a younger group (children 9-14 years of age, $\mathrm{CH}=11.1 \pm 1.1 \mathrm{mmHg}, P=0.01)$.

The more recent Antioxidants, Essential Lipids, Nutrition and Ocular Diseases (ALIENOR) Study ${ }^{52}$ also confirms lower $\mathrm{CH}$ values (mean $=9.4 \mathrm{mmHg}$ ) in an elderly population (mean age $=82$ ). They also found that the $\mathrm{CH}$ values within this group are associated with elevated plasma lowdensity lipoprotein cholesterol and higher lifetime ultraviolet radiation exposure, both of which may modify the biomechanical structure of the cornea.

\section{$\mathrm{CH}$ in glaucoma}

Early studies by Mangouritsas et al. ${ }^{7}$ found that $\mathrm{CH}$ in POAG subjects (mean $8.95 \mathrm{mmHg}$ ) was significantly lower than normal age-matched controls (mean $10.97 \mathrm{mmHg}$ ). Kaushik et al. ${ }^{53}$ found among a large cohort of 323 subjects, including normal OHT, PACG, POAG, and normal-tension glaucoma (NTG) subjects, that the POAG and NTG group had the lowest $\mathrm{CH}$ value (Table 1).

Further studies examining $\mathrm{CH}$ in glaucoma and OHT patients found $\mathrm{CH}$ values of POAG and NTG subjects were significantly lower than those of OHT subjects. ${ }^{8,53}$ In both normal and glaucoma patients, CCT increases as $\mathrm{CH}$ does, ${ }^{8,10,43,54-57}$ suggesting that corneal viscoelastic behavior may be influenced by its thickness.

There is a moderate positive correlation between $\mathrm{CH}$ and CCT, with $\mathrm{CH}$ being significantly lower in glaucoma in comparison to $\mathrm{OHT}^{8}{ }^{8}$ Following a multivariate analysis, $\mathrm{CH}$ was the only multivariate variable that was independently related to glaucoma, which could differentiate POAG from $\mathrm{OHT}^{8}$ Similarly, Pillunat et al. found a statistically significant correlation between ORA parameters with IOP, CCT, axial length, and age. ${ }^{58}$ They also found that POAG patients had the lowest adjusted $\mathrm{CH}$ values $(8.96 \pm 1.4 \mathrm{mmHg})$ in comparison to patients with OHT $(10.2 \pm 1.5 \mathrm{mmHg})$ and controls $(9.7 \pm 1.4 \mathrm{mmHg})$. When adjusted for the correlated factors, corneal biomechanical parameters may be helpful to stratify the severity of POAG patients, which determine the management plans for this group of patients. ${ }^{58}$ The same of group of researchers also evaluated the effect of trabeculectomy on corneal biomechanical properties and IOP measurements. They measured ORA parameters of 35 glaucoma patients undergoing first-time trabeculectomy with

Table 1. Corneal Hysteresis Values from Various Studies Measuring Across Glaucoma Subtypes

\begin{tabular}{|c|c|c|}
\hline Glaucoma subtype & First author ${ }^{\text {Ref. }}$ & $\mathrm{CH}$ value \\
\hline POAG vs. normal & Mangouritsas $^{7}$ & $8.95 \pm 1.27 \mathrm{mmHg}(\mathrm{POAG})$ vs. $10.97 \pm 1.59 \mathrm{mmHg}$ (normal) \\
\hline POAG vs. OHT & Pensyl $^{8} ;$ Kaushik $^{53}$ & $\begin{array}{l}7.58 \pm 1.38 \mathrm{mmHg}(\mathrm{POAG}) \text { vs. } 9.19 \pm 1.67 \mathrm{mmHg}(\mathrm{OHT}) \\
7.9 \pm 2.8 \mathrm{mmHg}(\mathrm{POAG}) \text { vs. } 9.2 \pm 1.9 \mathrm{mmHg}(\mathrm{OHT})\end{array}$ \\
\hline NTG vs. normal & Morita $^{11} ;$ Kaushik $^{53}$ & $\begin{array}{l}9.2 \pm 1.3 \mathrm{mmHg} \text { (NTG) vs. } 10.8 \pm 1.3 \mathrm{mmHg} \text { (normal) } \\
8.0 \pm 1.6 \mathrm{mmHg}(\mathrm{NTG}) \text { vs. } 9.5 \pm 1.4 \mathrm{mmHg} \text { (normal) }\end{array}$ \\
\hline PXFG vs. POAG & Ozkok $^{12} ;$ Ayala $^{60}$ & $\begin{array}{l}8.8 \pm 1.4 \mathrm{mmHg}(\mathrm{PXFG}) \text { vs. } 9.9 \pm 1.2 \mathrm{mmHg}(\mathrm{POAG}) \\
8.0 \pm 1.5 \mathrm{mmHg}(\mathrm{PXFG}) \text { vs. } 9.8 \pm 1.6 \mathrm{mmHg}(\mathrm{POAG})\end{array}$ \\
\hline PACG & Narayanaswamy $^{10} ;$ Kaushik $^{53}$ & $\begin{array}{l}9.1 \mathrm{mmHg}(\mathrm{PACG}) ; 9.4 \mathrm{mmHg}(\mathrm{POAG}) ; 10.4 \mathrm{mmHg} \text { (normal); } \\
9.3 \pm 1.5 \mathrm{mmHg}(\mathrm{PACG})^{53}\end{array}$ \\
\hline Congenital glaucoma & Kirwan $^{13}$ & $6.3 \mathrm{mmHg}$ \\
\hline
\end{tabular}

$\mathrm{CH}$, corneal hysteresis; NTG, normal-tension glaucoma; OHT, ocular hypertension; PACG, primary angle-closure glaucoma; POAG, primary open-angle glaucoma; PXFG, pseudoexfoliative glaucoma. 
mitomycin $\mathrm{C}$ and found there was no significant difference of $\mathrm{CH}$ values pretrabeculectomy and post-trabeculectomy $(\mathrm{CHpre}-\mathrm{trab}=7.75 \pm 1.5 \mathrm{mmHg}$ vs. $\mathrm{CH}$ post-trab $=7.62 \pm$ $1.7 \mathrm{mmHg}, P=0.72$ ). The corneal compensated IOP (IOPcc) of these patients was markedly and significantly reduced postoperatively and the accuracy of ORA-IOP measurements is not altered following this procedure.

Several studies have found $\mathrm{CH}$ to be lower among patients with NTG, especially if the eye showed evidence of progression. In asymmetric NTG, the worse-eye group had lower $\mathrm{CH}$ of $6.8 \mathrm{mmHg}$ when compared to the better-eye group $(\mathrm{CH}=7.6 \mathrm{mmHg})$. Among 82 patients with progressive NTG, patients who showed progression had lower $\mathrm{CH}$ $(\mathrm{CH}=9.4 \pm 1.3 \mathrm{mmHg})$ compared to patients who do not progress $(\mathrm{CH}=10.8 \pm 1.4 \mathrm{mmHg}) .{ }^{59}$

It is important to note that among all the glaucoma subtypes, patients with pseudoexfoliative glaucoma (PXFG) tend to have the lowest $\mathrm{CH}$ values. ${ }^{60}$ Studies that have compared PXFG and POAG have found $\mathrm{CH}$ values ranging between 7.6 and $8.8 \mathrm{mmHg}$ in PXFG groups, ${ }^{12,61}$ which are significantly lower than the POAG groups ( $\mathrm{CH}$ range $9.1-9.9 \mathrm{mmHg}$ ). PXFG is also associated with lower $\mathrm{CH}$ in comparison to patients with the pseudoexfoliative syndrome (PXS). Two large group studies investigated the ORA parameters of PXFG and PXS in a Turkish population and found almost similar $\mathrm{CH}$ value, which is lower in PXFG $(\mathrm{CH}=6.8 \pm 1.7 \mathrm{mmHg})$ when compared to PXS and healthy subjects $\left(\mathrm{CH}_{\mathrm{PXS}}=8.2 \pm 1.4 \mathrm{mmHg}\right.$ and $\mathrm{CH}_{\text {healthy }}=10.3 \pm 1.4 \mathrm{mmHg}$ ). ${ }^{62,63}$ Increased corneal stiffness in PXFG is possibly related to deposition of pseudoexfoliative material, which was identified through in vivo confocal microscopy as hyper-reflective substances on the corneal endothelium and anterior stroma. ${ }^{64}$

\section{$\mathrm{CH}$ as a risk factor for progression of glaucoma}

Congdon et al. conducted one of the first studies to assess the association between CCT and $\mathrm{CH}$ with glaucoma damage. ${ }^{65}$ They found thinner CCT was associated with higher cup disc ratio, lower $\mathrm{CH}$ was associated with progressive visual field worsening, and a weak correlation between $\mathrm{CCT}$ and $\mathrm{CH}$ existed.

Further studies have shown that eyes with lower $\mathrm{CH}$ have faster rates of visual field loss than those with higher $\mathrm{CH}^{66,67}$ De Moraes et al. found a mean global rate of visual field change in mean deviation of $-0.34 \pm 0.7 \mathrm{~dB} /$ year among 153 patients. ${ }^{66}$ Lower $\mathrm{CH}(7.5 \pm 1.4 \mathrm{mmHg})$ and thinner CCT $(525 \pm 34.2 \mu \mathrm{m})$ were noted in individuals with significant progression of visual field defect. ${ }^{66}$ Each $1 \mathrm{mmHg}$ lower $\mathrm{CH}$ value was associated with a $0.25 \% /$ year faster rate of visual field index (VFI) decline over time. ${ }^{67}$

These findings are also similar for NTG. ${ }^{15,59,68}$ Helmy et al. investigated 240 eyes and found $\mathrm{CH}$ was inversely proportional to the mean deviation in visual fields among patients with asymmetrical NTG. ${ }^{15}$ Park et al. found that eyes with progression of NTG had lower CCT $(530.2 \pm 38.6 \mu \mathrm{m})$, thinner average retinal nerve fiber layer (RNFL) thickness $(70.6 \pm 16.1 \mu \mathrm{m})$, and lower $\mathrm{CH}$ $(9.4 \pm 1.3 \mathrm{mmHg}){ }^{59}$ Rapid VF progression (defined as the upper 25th percentile group of median MD change over 3 years) occurred in NTG patients whose $\mathrm{CH}$ is low $(8.4 \pm 1.1 \mathrm{mmHg})$ and IOPcc is high $(15.8 \pm 1.8 \mathrm{mmHg}){ }^{68}$

Glaucomatous structural progression has also been shown to be associated with lower $\mathrm{CH}$. Age and $\mathrm{CH}$ were signifi- cantly associated with structural optic nerve progression as assessed through flicker chronoscopy. ${ }^{69}$ Among 5134 patients in the EPIC-Norfolk study, lower $\mathrm{CH}$ was associated with structural changes associated with glaucoma, including rim area and RNFL measured by scanning laser polarimetry. ${ }^{70}$

Most studies on $\mathrm{CH}$ and glaucoma progression to date have been retrospective, thus whether $\mathrm{CH}$ reflects a cause or as a result of progression cannot be determined. However, the Medeiros et al ${ }^{67}$ was a prospective study over 4 years and demonstrated a highly significant correlation between $\mathrm{CH}$ and VFI decline $(P<0.001)$. Baseline $\mathrm{CH}$ was the best predictive biomarker for subsequent progression. They also found that the effect of IOP on rates of progression depended on $\mathrm{CH}$, which conforms to the association of $\mathrm{CH}$ with deformation of optic nerve surface during transient elevations of IOP. ${ }^{14}$

\section{The ECM}

The ECM is fundamental in maintaining the form and function of soft connective tissue. ${ }^{71}$ The main constituents of ECM that provide mechanical properties for a tissue are elastic fibers, collagens, GAGs, and proteoglycans. ${ }^{24} \mathrm{Ma}-$ terial stiffness is defined as how stress changes in response to deformation ${ }^{24}$ and this is maintained by collagens within the ECM. Elastin is another key ECM protein, which plays a role in elasticity to allow flexibility and stretch-relaxation capacity of tissues such as large arteries, lung, ligaments, and skin. ${ }^{72}$ In the arterial wall, the elastic fibers that are damaged due to the aging process are not replaced as elastin expression is switched off. This causes more collagen production, which decreases the elastin:collagen ratio and shifts the arterial mechanical properties into the stiffer range of the collagen fibers. ${ }^{73}$

The ECM has a reservoir of regulatory molecules, including cytokines, hormones, and extracellular microRNA (miRNA). These regulatory molecules are important for a bidirectional signal transduction process to promote mechanical homeostasis as a response to extrinsic stress signals onto the ECM. ${ }^{74}$ In particular, the ECM turnover is necessary to maintain mechanical homeostasis of soft connective tissue in response to increased stress load. Computational models of the ECM suggest that to achieve mechanical homeostasis, it depend on factors including rates of ECM production, rates of ECM removal, the mechanical properties of the ECM constituents, and the degree of prestress value that is built into the constituents. ${ }^{75}$ The short-term response to increased loading is characterized by matrix reorganization and collagen cross-linking, and in the long term, this is balanced by matrix degradation and deposition of the new constituents under the appropriate prestress level. ${ }^{24}$ The tissue's form and function can only be maintained if the structural constituents that are degraded are replaced with new constituents that have the same properties and in the same ratio, including the same prestress-induced stiffness. ${ }^{76}$ If there is imbalanced remodeling and degradation, pathologic signaling will then induce fibrotic responses leading to permanent stiffness of the tissue. ${ }^{77}$

\section{Cross-Linking and Tissue Stiffness}

The major collagen cross-linking proteins found within the ECM include LOX and TG2, both of which have been 
described in relationship to tissue stiffness. The critical role of tissue stiffness in the pathophysiology of disease has emerged through numerous studies related to cancer. Increased stiffness as a result of continuous tumor microenvironment remodeling is a hallmark feature of aggressive tumor progression. ${ }^{27}$ Each of the collagen cross-linking proteins in this review appears to have a role in tissue stiffness in cancer pathophysiology, which may also provide an insight of its similar role for ocular stiffness in glaucoma.

Breast cancer tissue, for example, can be 10-fold stiffer than normal breast tissue ${ }^{78}$ and also appear stiffer on elastography when compared to benign tumors. ${ }^{79}$ The breast tumor-associated ECM has been shown to have collagen Type 1 and fibronectin as the most abundant ECM components deposited. ${ }^{80}$ Collagen cross-linking in response to increased collagen deposition is mediated by the activity of LOX proteins, which has been described to increase the invasiveness of many types of cancer cells ${ }^{81,82}$ and tumor metastasis. $^{83}$

TG2 has also been found to catalyze cross-linking of ECM proteins, including collagen, fibronectin, and elastin. ${ }^{84}$ TG2 accounts for a variety of biochemical activities, including adhesion, migration, growth, survival, apoptosis, differentiation, and ECM organization. ${ }^{85}$ Their activities are calcium dependent, and in relationship to ECM organization, TG2 can render ECM proteins resistant to degradation $^{86}$ and also induce profibrotic effector functions. ${ }^{84}$ The expression of TG2 is elevated in many fibrotic diseases such as pulmonary, ${ }^{87}$ hepatic, ${ }^{88}$ and kidney ${ }^{89}$ fibrosis. TG2 has also been implicated in cancer, where it is associated with cancer cell migration and invasion. ${ }^{90}$

In contrast to LOX and TG2, AGEs elicit synergism with oxidative stress. AGEs lead to the generation of reactive oxygen species (ROS) and AGE production is promoted by oxidative stress. ${ }^{91}$ They are thought to exacerbate disease progression through 2 general mechanisms. First, these modified proteins form detergent-insoluble, protease-resistant nondegradable aggregates through cross-linking processes and impair normal cellular/tissue functions. Second, AGEs modulate cellular function through binding to specific receptors, receptor for AGE (RAGE). Activation of RAGE initiates a wide range of abnormal responses in cells and tissues such as inappropriate expression of growth factors, alterations in growth dynamics, accumulation of ECM, promotion of vasoregulatory dysfunction, and initiation of death pathways. $^{92}$ These 2 mechanisms are found most relevant in context with diabetes and aging where accumulative levels of AGEs are highest and renal function may be impaired.

\section{Ocular Stiffness in Glaucoma}

It is hypothesized that stiffening of ocular structures, including cornea, sclera, and LC, may relate to the pathogenesis of glaucoma. ${ }^{93}$ Wells et al. ${ }^{14}$ found $\mathrm{CH}$ to be lower in glaucoma patients, and $\mathrm{CH}$ significantly correlated with optic disc compliance in contrast to CCT. They also found that $\mathrm{CH}$ was associated with increased deformation of optic nerve surface during transient elevations of IOP. These findings support their hypothesis that if optic nerve rigidity was related to cross-linking between collagen fibrils in the laminae, then it is expected that the greater LC stiffness was associated with lower hysteresis. Lanzagorta-Aresti et al. found a relevant outcome in context to this hypothesis when they showed $\mathrm{CH}$ in 61 eyes with OHT or POAG was significantly correlated with LC displacement $\left(R^{2}=0.48, P=0.03\right)$ after medical lowering of the IOP, meaning the least reversal of cupping (LC displacement) following medical IOPlowering treatment occurs in the stiffest cornea, that is, lower $\mathrm{CH}^{94}$

Multiple mechanisms, including glucose-mediated crosslinking, calcium and lipid accumulation, oxidative stress, and enzymatic proteolysis, are implicated in elastic fiber remodeling. The pathogenesis of glaucoma is also likely related to age-related stiffening at the $\mathrm{ONH}$, and within the TM and LC, with increased age as a major risk factor for glaucoma development. The similarities of ECM constituents of the cornea, TM, and LC may also imply that similar cross-linking process can occur within these structures to result in ocular stiffness (Table 2).

The ECM of the human ONH undergoes age-related changes at the LC, which underpin the age- related optic neuropathy as found in glaucoma. Albon et al. found changes in the collagenous and noncollagenous components of the ECM with increasing age. ${ }^{29,95}$ There is an increase of total collagen and collagen cross-links in the aged LC. ${ }^{29}$ Noncollagenous components of ECM of the LC include fibronectin, elastin, and sulfated GAGs. There is an increase of the elastin content (from $7 \%$ in the $0-9$ age group to $28 \%$ in the $80-89$ age group), with decreased fibronectin and GAGs, all of which may contribute to changes in mechanical integrity of the $\mathrm{ONH} .{ }^{95}$ These changes reduce the tissue resilience in response to strain. They followed through these findings by conducting a study to investigate the mechanical compliance of the LC with age. ${ }^{96}$ They found that there is an increased stiffness of the LC, whereby the ability to regain its original shape and size after removal of pressure is reduced. This may be related to the more rigid cribriform

Table 2. A Summary of the Extracellular Matrix Constituents of the Cornea, Trabecular Meshwork, and Optic Nerve Head, Which May Suggest Similar Cross-Linking Processes Occur Within These Ocular Structures

Ocular structure

Cornea

Trabecular meshwork Optic nerve head
ECM constituents

Stroma-collagen type I, III, V and VI; Descemet's membrane-collagen type IV, VIII; GAGs+proteoglycans, including keratin sulfate, chondroitin sulfate, and dermatan sulfate; fibronectin; laminin

Corneoscleral meshwork-collagen type I, III, IV, V; cribriform layer-collagen

type I, III, IV, VIII; elastic fibers; GAGs and proteoglycans; fibronectin; matricellular proteins Prelaminar-collagen type III, IV, and V; cribriform plates-collagen type I, III, IV, and VIII, fibronectin, and laminin

ECM, extracellular matrix; GAGs, glycoaminoglycans.

Source: Marshall et al. ${ }^{20}$ 
plates found in an elderly LC, suggesting an increased susceptibility to plastic flow and permanent deformation contributing to axonal damage as seen in glaucoma.

There is now increasing evidence that the biomechanical properties of the TM is altered in glaucoma due to increased collagen cross-linking of the ECM, which results in decreased ECM turnover, abnormal ECM accumulation, and eventually tissue stiffness. ${ }^{97}$ Last et al. conducted a study to compare the stiffness of human TM in normal and glaucomatous tissue using atomic force microscopy to measure elastic modulus. ${ }^{98}$ They found a 20 -fold increased stiffness of the glaucomatous TM $(80.8 \mathrm{kPa})$ compared to normal TM $(4.0 \mathrm{kPa})$, and subsequent mathematical modeling showed substantial impairment in outflow facility with increased TM stiffness.

In normal human cornea, loss of stromal organization as seen in advancing age or corneal pathology results in altered corneal biomechanics. ${ }^{17}$ Daxer et al. ${ }^{99}$ found that there is a small, but significant age-related increase in the collagen fibril diameter with increased intermolecular spacing and elongation of the collagen fibrils as a result of continual deposition of collagen molecules. These findings agree with a study by Malik et al., ${ }^{100}$ in which they found an increase in the cross-sectional area within each corneal collagen molecule (from 3.04 to $3.46 \mathrm{~nm}^{2}$ ) with advancing age. They also suggested that this may be due to an increase in nonenzymatic cross-linking between collagen molecules, shown by an increase in glycation and AGEs using fluorescence emission.

\section{Collagen Cross-Linking Proteins in Glaucoma}

LOX, TG2, and AGEs may have a role in the increased collagen cross-linking processes that lead to ocular stiffness in glaucoma. Table 3 summarizes the mechanism of action of these proteins and their relationship to glaucoma that has been identified so far.

\section{LOX/LOXL1}

There are 5 members in the LOX family and they are copper-dependent enzymes that oxidize lysine residues in elastin and collagen to form covalent cross-links that render these fibers insoluble in the ECM. ${ }^{101}$ The LOXL1 or LOX homolog type 1 enzyme is necessary for tropoelastin crosslinking and elastic fiber formation, maintenance, and re- modeling. ${ }^{102}$ LOX and LOXL1 are very similar in terms of their catalytic domain. ${ }^{103}$ Our best knowledge on the LOX family in glaucoma is based on studies in relationship to pseudoexfoliative syndrome (PXS). Thorleifsson et al. ${ }^{104}$ was the first to describe the association of LOXL1 in exfoliation glaucoma following a genome-wide association study (GWAS) of the Icelandic population. They identified 2 single-nucleotide polymorphisms (rs1048661 and rs3825942) in exon 1 of the LOXL1 gene associated with an increased risk of developing pseudoexfoliative glaucoma (PXFG).

The pathogenetic concept behind PXS is it is a type of stress-induced elastosis associated with excessive production and abnormal aggregation of elastic fiber components and abnormal enzymatic cross-linking processes. ${ }^{105}$ In pseudoexfoliative glaucoma (PXFG), stiffness of the sclera and peripapillary sclera (ppSc) is possibly related to LOXL1 deficiency. ${ }^{106}$ Dysregulation of the LOXL1 causes elastic fibers to become highly resistant to degradation or turnover ${ }^{102}$ and is associated with ultrastructural alterations of the elastic networks of the laminar beams in PXS eyes. ${ }^{106}$ LOXL1 genes are expressed in cultured human TM and may be partly responsible for the increased aqueous outflow resistance in glaucoma due to abnormal cross-linking signaling in the $\mathrm{ECM}^{107}$ and chronic accumulation of fibrillar PEX aggregates in the outflow pathways. ${ }^{108}$ Schlotzer-Schrehardt et al. ${ }^{108}$ found that LOXL1 expression was significantly increased in early stages of PXFG; however, at advanced stages, the expression is decreased, which promotes abnormal elastogenesis.

At present, there is inconsistent association of LOXL1 with POAG ${ }^{109-111}$; however, a recent GWAS in an Asian population identified 7 novel susceptibility loci associated with POAG, including LOXL1. ${ }^{112}$

\section{Tissue transglutaminase (TG2)}

TG2 is a calcium-dependent enzyme responsible for protein cross-linking of lysine and glutamine residues. ${ }^{113}$ The resultant cross-linked ECM protein would be highly resistant to proteolysis and degradation. ${ }^{114}$ Recent data by Raychaudhuri et al. showed elevated expression of TG2 in the TM increases $\mathrm{N}$-e(G-glutamyl) lysine cross-linking in mice TM. This consequently increases aqueous outflow resistance resulting in IOP elevation. ${ }^{31}$

Tovar-Vidales et al. ${ }^{115}$ studied the differences in expression and activity of TG2 between normal and glaucoma TM

Table 3. A Description of 3 Collagen Cross-Linkers That May Be Implicated in OCular Stiffness in Glaucoma

Collagen cross-linking proteins

LOX/LOXL1

TG2

AGEs

\section{Description}

Copper-dependent enzyme; cross-linking of lysine residues in elastin and collagen; induced by TGF- $\beta$; implicated as a risk factor in the development of pseudoexfoliation glaucoma (PXFG) ${ }^{104}$

Calcium-dependent enzyme; cross-linking of lysine and glutamine residue; induced by TGF- $\beta$; TGM2 is present in aqueous humor with increased expression and enzyme activity in glaucomatous eyes ${ }^{31}$

Produced by nonenzymatic glycation of proteins; forms cross-links between neighboring proteins; glycation of proteins such as collagen is well recognized in aging and diabetes; increased AGE accumulation and signaling of RAGE in glaucomatous tissue ${ }^{28}$ 
cells. They found that TG2 are present in both normal and glaucoma TM cells; however, there is an increased TG2 expression and enzyme activity in glaucoma TM cells. In addition, fibronectin-a glycoprotein, which binds ECM components that is mediated by TG2, was also found to be elevated in Schlemm's Canal of glaucomatous TM. ${ }^{115}$ These results support the potential role of TG2 may be pathogenic in altering the biomechanics of TM, thus increasing outflow resistance in glaucomatous eyes. ${ }^{115}$

\section{The $\mathrm{ONH}$ and collagen cross-linking proteins}

Zeimer and Ogura investigated the mechanical compliance of $\mathrm{ONH}$ in glaucoma patients ex vivo. ${ }^{116}$ They defined $\mathrm{ONH}$ stiffness as low/small displacement of the $\mathrm{ONH}$ when the displacement is measured by increasing the IOP to $60 \mathrm{mmHg}$ from a resting IOP of $12 \mathrm{mmHg}$. The eyes that had more severe glaucomatous changes exhibit a reduced $\mathrm{ONH}$ displacement. They suggested their results might be interpreted as a cumulative change in elastic properties of the LC, which is likely due to a change in the ECM of the tissue. This corresponds with findings by many studies that described altered collagen metabolism in glaucoma leading to a change in the physical properties of the LC. ${ }^{117-119}$

A study by our group reported on global and ECMfocused differential gene expression between POAG and normal LC cells using microarray analysis. ${ }^{30}$ They identified 50 most expressed genes in POAG LC cells, which reflected the multimechanistic pathology of glaucoma that included a combination of ECM, cytoskeletal, angiogenic, neuronal, and developmental genes. Of particular interest from this study is the higher expression of the ECM-related gene LOX in the POAG LC cell lines ( 0.5 fold increase).

We recently examined the messenger RNA (mRNA) expression of TG2 and LOX in human LC cells using standard real-time polymerase chain reaction. Analysis of TG2 and LOX transcripts showed a significantly higher level of both genes in glaucoma LC cells in comparison to normal LC cells (Fig. 2). ${ }^{120}$ This unpublished finding suggests that active collagen cross-linking can also occur in glaucoma LC cells due to elevated expression of major cross-linking proteins such as LOX and TG2, which may subsequently alter the mechanical properties and stiffening of the LC, leading to progressive neurodegeneration of the $\mathrm{ONH}$.

\section{Advanced glycation end products}

AGEs are by-products of nonenzymatic glycation reactions between reactive carbonyl groups of compounds (such as glucose) with proteins, lipids, or nucleic acids. ${ }^{121}$ A complex series of reactions (over months or years) leads to metabolic by-products of glycolysis, which interact with extracellular proteins to form - that can bridge between the free amino groups of neighboring proteins to form intermolecular cross-links.

AGEs and the eye. AGEs have been found in the aqueous humor, lens, retina, Bruch's membrane, and optic nerve. ${ }^{121}$ Accumulation of AGEs has been found in corneal endothelial cells in elderly populations. ${ }^{122}$ Corneal collagen modification following advanced Maillard reactions has been shown to occur in the cornea of diabetics. ${ }^{123}$ Nonenzymatic collagen cross-linking causes an increase in cross-

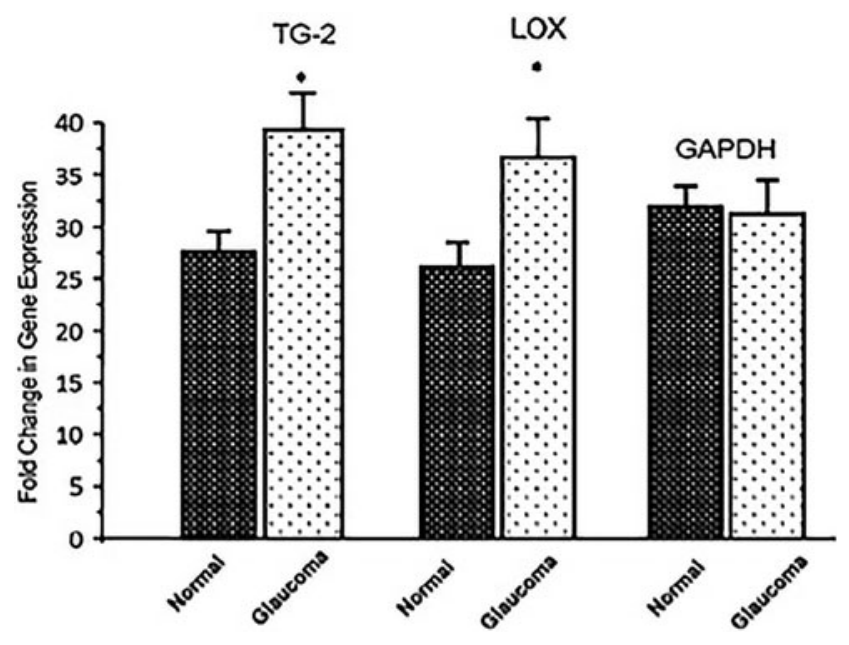

FIG. 2. TG2 and LOX expression in normal and glaucoma LC cells. mRNA expression of TG2 and LOX was performed by RT-PCR in normal $(n=3)$ and glaucoma $(n=3)$ LC cells lines. Analysis of TG2 and LOX showed that both genes were significantly expressed at higher level in glaucoma LC cells compared to normal LC cells. ${ }^{119}$ LC, lamina cribrosa; LOX, lysyl oxidase; mRNA, messenger RNA; RTPCR, real-time polymerase chain reaction; TG2, tissue transglutaminase.

sectional areas of collagen fibrils ${ }^{99}$ and fibrillar molecules, ${ }^{100}$ and a decrease of interfibrillar spacing related to changes in proteoglycan composition of the interfibrillar matrix. ${ }^{124}$ This results in increased deposition of ECM in response to cell and matrix disorganization. Similar to the aging process, the mechanism of corneal stiffness is likely related to ECM modification and collagen cross-linking; in glaucoma and diabetes, this could be at an accelerated rate, potentially in the presence of AGEs. As an example, collagen cross-linking mediated by AGEs has been suggested to explain the significant increase in stiffness of diabetic $\mathrm{ONH}$ in rats. At $5 \%$ strain, the stress of the $\mathrm{ONH}$ in diabetic rats $(897 \pm 295 \mathrm{kPa})$ was significantly higher than nondiabetic, control rats $(671 \pm 246 \mathrm{kPa}, P=0.011){ }^{125}$

AGEs and glaucoma. There is growing evidence of oxidative stress as a disease process in glaucomatous neurodegeneration. ${ }^{126}$ AGEs lead to the generation of ROS and AGE production is promoted by oxidative stress. ${ }^{91}$ Hondur et al. ${ }^{127}$ identified that AGEs and protein carbonyls are promising candidates as oxidative stress-related molecular biomarkers for clinical predictions of glaucoma when they found a 3.1-fold increase of AGE levels in glaucomatous aqueous humor samples in comparison to normal samples $(17.6 \pm 4.6$ vs. $5.7 \pm 2.3 \mu \mathrm{g} / \mathrm{mL})$. Analysis of the aqueous humor is likely useful to provide relevant and specific glaucoma-related information due to its close proximity to disease sites of glaucoma, such as the TM and Schlemm's Canal.

However, AGEs mainly accumulate on long-lived proteins in tissues such as the LC and ONH. Tezel et al. ${ }^{28}$ found increased AGE accumulation in glaucomatous tissues in the retina and $\mathrm{ONH}$, supporting the theory that an accelerated aging process accompanies neurodegeneration in glaucomatous eyes. They also found increased signaling of RAGE 
within retinal glial cells in glaucomatous tissue. Furthermore, substances such as glyceraldehyde and methylglyoxal, which are precursors of AGEs through the Maillard reaction, may also have a role in altering the biomechanical properties of the ECM. Spoerl et al. found an increased stiffness of human LC and ppSc after these structures were treated with glyceraldehyde and methylglyoxal, respectively. ${ }^{128}$ In contrast, collagenase $\mathrm{A}$ was found to reduce the stiffness of the tissues. ${ }^{128}$ This findings support that AGEs can induce changes of the biomechanical behavior of the LC and ppSc, which could potentially be reversed, leading to the development of therapeutic options in glaucoma.

\section{Targeting Collagen Cross-Linking Proteins as a Potential Therapeutic Strategy in Glaucoma}

Based on numerous studies of LOX, TG2, and AGEs in their role in cancer progression and fibrosis, it has been suggested that these 2 enzymes are potential targets for cancer therapy. For example, an inhibitory monoclonal antibody targeting LOXL2 resulted in a marked reduction in activated fibroblasts, desmoplasia, and endothelial cells, decreased production of growth factors and cytokines, and decreased transforming growth factor (TGF)- $\beta$ pathway signaling in xenograft models of cancer as well as lung and liver fibrosis. ${ }^{129}$ Similarly, inhibition of TG2 showed potential novel target for pulmonary fibrosis ${ }^{84}$ as it decreases the profibrotic effector function of TG2.

LOX is increasingly considered a therapeutic target and there is potential in glaucoma treatment. There is an LOX cross-linking inhibitor- $\beta$-aminopropionitrile (BAPN), which has been shown to be effective in reducing ECM stiffness in artherosclerosis $^{130}$ and murine models of tumors and fibrosis. ${ }^{131,132}$ There may be potential for BAPN to be used to reduce TM stiffness. It was found that TM treatment with BAPN significantly increased outflow rates by 1.5 - to 2 -fold in normal human and porcine anterior chamber perfusion culture. $^{133}$

There is also potential for TG2 as therapeutic target. TG2 knockout mice exhibit reversal of disease phenotypes in neurodegenerative and chronic inflammatory disease models. ${ }^{134}$ In relationship to glaucoma, Raychaudhuri et al. followed on their initial findings of higher expression of TG2 in transduced mice that results in an increase of IOP and decrease of outflow facility. ${ }^{31}$ They subsequently tested the effect of TG2 knockout on IOP of TG2-floxed mice. ${ }^{135}$ They found that TG2 knockout significantly decreases the IOP and in TGF- $\beta 2$-induced OHT mice. The outflow facility following TG2 knockout is also improved in TGF- $\beta 2-$ induced eyes.

Alagebrium, which is also termed as ALT-117, breaks AGE cross-links and prevents accumulation of collagen and AGEs. It is has been found to improve arterial compliance of the cardiovascular system. ${ }^{136}$ ALT-117 has also been found to improve the left ventricular stiffness in healthy older individuals. ${ }^{137}$ Kiland et al. ${ }^{138}$ investigated the effect of alagebrium on anterior segment morphology and ocular AGE and RAGE on aged rhesus monkey. Alagebrium did not have any major effect on IOP or outflow facility; however, they found formation of focal plaques within the juxtacanalicular network. Due to this, they concluded that AGE cross-link breaker is an unlikely approach for glaucoma therapy.

\section{OCULAR / CORNEAL STIFFNESS IN GLAUCOMA AND COLLAGEN CROSS-LINKING PROTEINS}

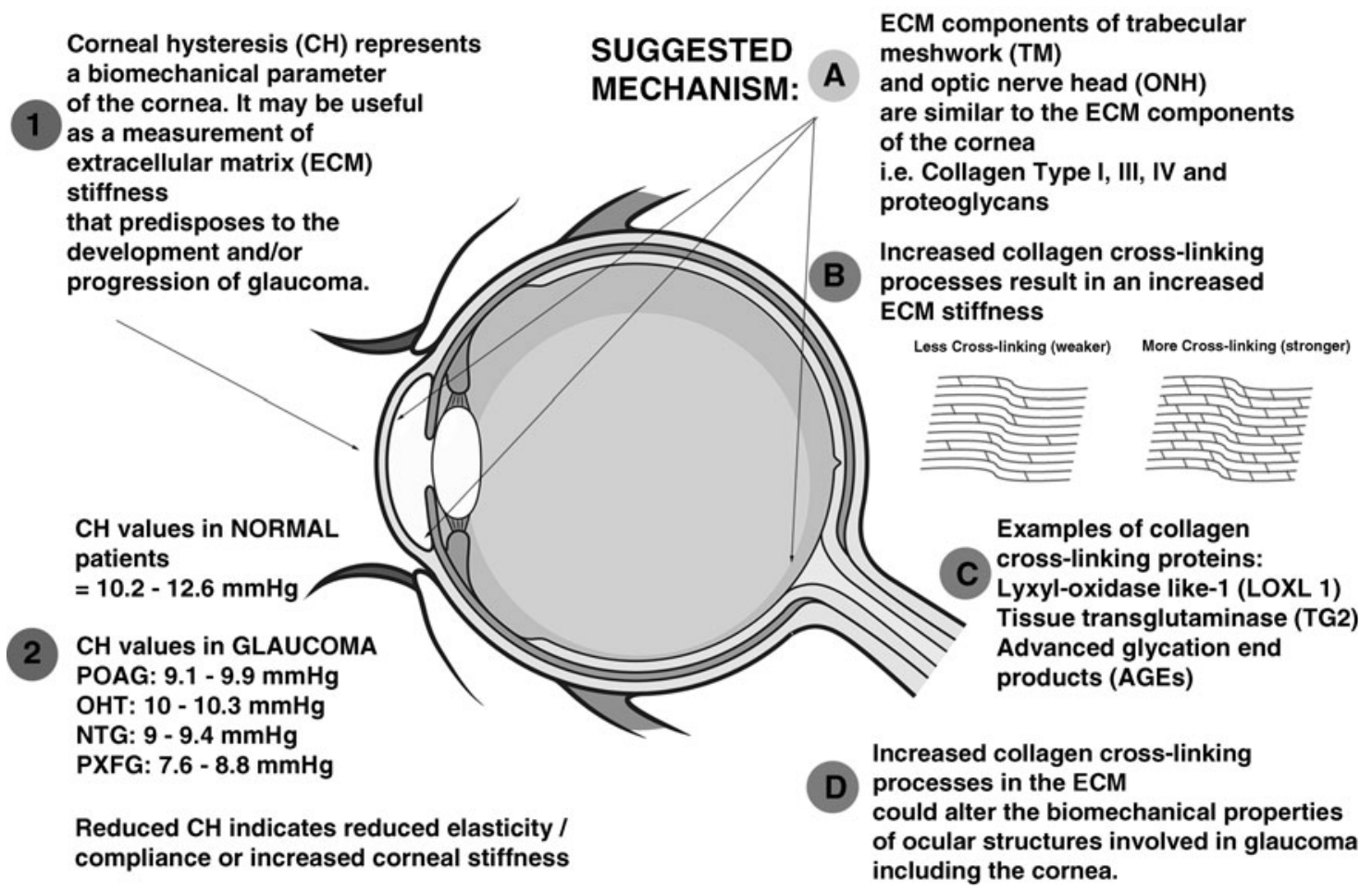

FIG. 3. This infograph summarizes our review article that suggests the relationship between collagen cross-linking proteins and ocular/corneal stiffness. 


\section{Conclusion}

This review provides an understanding of the biomechanical properties of the cornea in relationship to glaucoma. Corneal, TM, and ONH stiffness occur with aging, findings that are exacerbated in glaucomatous change. The ECM plays an important role in the mechanical homeostasis of a tissue as it balances its structural constituents in response to stress loads. The ECM composition of the cornea, TM, and $\mathrm{ONH}$ is very similar, in particular, its collagen distribution. Abnormal collagen cross-linking results in tissue stiffening with resistance to degradation within the ECM. Collagen cross-linking proteins such as LOX, TG2, and AGEs have been implicated in glaucoma and its downstream effects may be seen as a risk factor for development and/or progression of glaucoma. Figure 3 summarizes the potential relationship between collagen cross-linking proteins and ocular/corneal stiffness, whereby the basis of the proposed mechanism is in context to the ECM alteration seen in the pathophysiology of cancer and fibrotic diseases.

The relationship between corneal biomechanical properties and collagen cross-linking provides a theoretical mechanism that may explain the progressive ocular stiffness process demonstrated in normal aging and is exaggerated in glaucoma. Further investigative studies are required to identify potential cross-linking biomarkers and therapeutic strategies in preventing the degenerative process of glaucoma.

\section{Author Disclosure Statement}

The authors declare they have no commercial or financial interests.

\section{Funding Information}

No funding was received for this article.

\section{References}

1. Gordon, M.O., Beiser, J.A., Brandt, J.D., et al. The Ocular Hypertension Treatment Study: baseline factors that predict the onset of primary open-angle glaucoma. Arch. Ophthalmol. 120:714-720; discussion 829-730, 2002.

2. The Advanced Glaucoma Intervention Study (AGIS): 7. The relationship between control of intraocular pressure and visual field deterioration. The AGIS Investigators. Am. J. Ophthalmol. 130:429-440, 2000.

3. Kass, M.A., Heuer, D.K., Higginbotham, E.J., et al. The Ocular Hypertension Treatment Study: a randomized trial determines that topical ocular hypotensive medication delays or prevents the onset of primary open-angle glaucoma. Arch. Ophthalmol. 120:701-713; discussion 829-730, 2002.

4. The effectiveness of intraocular pressure reduction in the treatment of normal-tension glaucoma. Collaborative Normal-Tension Glaucoma Study Group. Am. J. Ophthalmol. 126:498-505, 1998.

5. Leske, M.C., Heijl, A., Hussein, M., Bengtsson, B., Hyman, L., and Komaroff, E. Factors for glaucoma progression and the effect of treatment: the Early Manifest Glaucoma Trial. Arch. Ophthalmol. 121:48-56, 2003.

6. Deol, M., Taylor, D.A., and Radcliffe, N.M. Corneal hysteresis and its relevance to glaucoma. Curr. Opin. Ophthalmol. 26:96-102, 2015.

7. Mangouritsas, G., Morphis, G., Mourtzoukos, S., and Feretis, E. Association between corneal hysteresis and central corneal thickness in glaucomatous and nonglaucomatous eyes. Acta Ophthalmol. 87:901-905, 2009.

8. Pensyl, D., Sullivan-Mee, M., Torres-Monte, M., Halverson, K., and Qualls, C. Combining corneal hysteresis with central corneal thickness and intraocular pressure for glaucoma risk assessment. Eye (Lond). 26: 1349-1356, 2012.

9. Castro, D.P., Prata, T.S., Lima, V.C., Biteli, L.G., de Moraes, C.G., and Paranhos Jr., A. Corneal viscoelasticity differences between diabetic and nondiabetic glaucomatous patients. J. Glaucoma 19:341-343, 2010.

10. Narayanaswamy, A., Su, D.H., Baskaran, M., et al. Comparison of ocular response analyzer parameters in chinese subjects with primary angle-closure and primary open-angle glaucoma. Arch. Ophthalmol. 129:429-434, 2011.

11. Morita, T., Shoji, N., Kamiya, K., Fujimura, F., and Shimizu, K. Corneal biomechanical properties in normaltension glaucoma. Acta Ophthalmol. 90:e48-e53, 2012.

12. Ozkok, A., Tamcelik, N., Ozdamar, A., Sarici, A.M., and Cicik, E. Corneal viscoelastic differences between pseudoexfoliative glaucoma and primary open-angle glaucoma. J. Glaucoma 22:740-745, 2013.

13. Kirwan, C., O'Keefe, M., and Lanigan, B. Corneal hysteresis and intraocular pressure measurement in children using the reichert ocular response analyzer. Am. J. Ophthalmol. 142:990-992, 2006.

14. Wells, A.P., Garway-Heath, D.F., Poostchi, A., Wong, T., Chan, K.C., and Sachdev, N. Corneal hysteresis but not corneal thickness correlates with optic nerve surface compliance in glaucoma patients. Invest. Ophthalmol. Vis. Sci. 49:3262-3268, 2008.

15. Helmy, H., Leila, M., and Zaki, A.A. Corneal biomechanics in asymmetrical normal-tension glaucoma. Clin. Ophthalmol. 10:503-510, 2016.

16. Snell, R.S., and Lemp, M.A. Clinical Anatomy of the Eye. 2nd ed. Washington, DC: Blackwell Science; 1998.

17. Kotecha, A. What biomechanical properties of the cornea are relevant for the clinician? Surv. Ophthalmol. 52(Suppl 2):S109-S114, 2007.

18. Michelacci, Y.M. Collagens and proteoglycans of the corneal extracellular matrix. Braz. J. Med. Biol. Res. 36: 1037-1046, 2003.

19. Briggaman, R.A. Biochemical composition of the epidermal-dermal junction and other basement membrane. J. Invest. Dermatol. 78:1-6, 1982.

20. Marshall, G.E., Konstas, A.G., and Lee, W.R. Collagens in ocular tissues. Br. J. Ophthalmol. 77:515-524, 1993.

21. Tsuchiya, S., Tanaka, M., Konomi, H., and Hayashi, T. Distribution of specific collagen types and fibronectin in normal and keratoconus corneas. Jpn. J. Ophthalmol. 30: 14-31, 1986.

22. Nakayasu, K., Tanaka, M., Konomi, H., and Hayashi, T. Distribution of types I, II, III, IV and V collagen in normal and keratoconus corneas. Ophthalmic Res. 18:1-10, 1986.

23. Terai, N., Raiskup, F., Haustein, M., Pillunat, L.E., and Spoerl, E. Identification of biomechanical properties of the cornea: the ocular response analyzer. Curr. Eye Res. 37:553-562, 2012.

24. Humphrey, J.D., Dufresne, E.R., and Schwartz, M.A. Mechanotransduction and extracellular matrix homeostasis. Nat. Rev. Mol. Cell Biol. 15:802-812, 2014.

25. Sherratt, M.J. Tissue elasticity and the ageing elastic fibre. Age (Dordr). 31:305-325, 2009. 
26. Robert, L., Robert, A.M., and Fulop, T. Rapid increase in human life expectancy: will it soon be limited by the aging of elastin? Biogerontology 9:119-133, 2008.

27. Handorf, A.M., Zhou, Y., Halanski, M.A., and Li, W.J. Tissue stiffness dictates development, homeostasis, and disease progression. Organogenesis 11:1-15, 2015.

28. Tezel, G., Luo, C., and Yang, X. Accelerated aging in glaucoma: immunohistochemical assessment of advanced glycation end products in the human retina and optic nerve head. Invest. Ophthalmol. Vis. Sci. 48:1201-1211, 2007.

29. Albon, J., Karwatowski, W.S., Avery, N., Easty, D.L., and Duance, V.C. Changes in the collagenous matrix of the aging human lamina cribrosa. Br. J. Ophthalmol. 79:368$375,1995$.

30. Kirwan, R.P., Wordinger, R.J., Clark, A.F., and O'Brien, C.J. Differential global and extra-cellular matrix focused gene expression patterns between normal and glaucomatous human lamina cribrosa cells. Mol. Vis. 15:76-88, 2009.

31. Raychaudhuri, U., Millar, J.C., and Clark, A.F. Tissue transglutaminase elevates intraocular pressure in mice. Invest. Ophthalmol. Vis. Sci. 58:6197-6211, 2017.

32. Brandt, J.D., Beiser, J.A., Kass, M.A., and Gordon, M.O. Central corneal thickness in the Ocular Hypertension Treatment Study (OHTS). Ophthalmology 108:1779-1788, 2001.

33. Gunvant, P., O'Leary, D.J., Baskaran, M., Broadway, D.C., Watkins, R.J., and Vijaya, L. Evaluation of tonometric correction factors. J. Glaucoma 14:337-343, 2005.

34. Elsheikh, A., Gunvant, P., Jones, S.W., Pye, D., and Garway-Heath, D. Correction factors for Goldmann tonometry. J. Glaucoma 22:156-163, 2013.

35. Leske, M.C., Heijl, A., Hyman, L., Bengtsson, B., Dong, L., and Yang, Z. Predictors of long-term progression in the Early Manifest Glaucoma Trial. Ophthalmology 114: 1965-1972, 2007.

36. Brandt, J.D. Central corneal thickness-tonometry artifact, or something more? Ophthalmology 114:1963-1964, 2007.

37. Rogers, D.L., Cantor, R.N., Catoira, Y., Cantor, L.B., and WuDunn, D. Central corneal thickness and visual field loss in fellow eyes of patients with open-angle glaucoma. Am. J. Ophthalmol. 143:159-161, 2007.

38. Chauhan, B.C., Hutchison, D.M., LeBlanc, R.P., Artes, P.H., and Nicolela, M.T. Central corneal thickness and progression of the visual field and optic disc in glaucoma. Br. J. Ophthalmol. 89:1008-1012, 2005.

39. Medeiros, F.A., Sample, P.A., Zangwill, L.M., Bowd, C., Aihara, M., and Weinreb, R.N. Corneal thickness as a risk factor for visual field loss in patients with preperimetric glaucomatous optic neuropathy. Am. J. Ophthalmol. 136: 805-813, 2003.

40. Reichert Technologies. Ocular response analyzer. www .reichert.com/product_details.cfm?skuId=2976\&skuTk=10 36239258 - .V3JGueYrJ-U (accessed June 28, 2016).

41. Zhang, B., Shweikh, Y., Khawaja, A.P., Gallacher, J., Bauermeister, S., and Foster, P.J. Associations with corneal hysteresis in a population cohort: results from 96010 UK Biobank participants. Ophthalmology. 126: 15001510, 2019.

42. Shah, S., Laiquzzaman, M., Bhojwani, R., Mantry, S., and Cunliffe, I. Assessment of the biomechanical properties of the cornea with the ocular response analyzer in normal and keratoconic eyes. Invest. Ophthalmol. Vis. Sci. 48: 3026-3031, 2007.

43. Touboul, D., Roberts, C., Kerautret, J., et al. Correlations between corneal hysteresis, intraocular pressure, and cor- neal central pachymetry. J. Cataract Refract. Surg. 34: 616-622, 2008.

44. Laiquzzaman, M., Bhojwani, R., Cunliffe, I., and Shah, S. Diurnal variation of ocular hysteresis in normal subjects: relevance in clinical context. Clin. Exp. Ophthalmol. 34: 114-118, 2006.

45. Kida, T., Liu, J.H., and Weinreb, R.N. Effects of aging on corneal biomechanical properties and their impact on 24-hour measurement of intraocular pressure. Am. J. Ophthalmol. 146:567-572, 2008.

46. Carbonaro, F., Andrew, T., Mackey, D.A., Spector, T.D., and Hammond, C.J. The heritability of corneal hysteresis and ocular pulse amplitude: a twin study. Ophthalmology 115:1545-1549, 2008.

47. Freeman, E.E., Roy-Gagnon, M.H., Descovich, D., Masse, H., and Lesk, M.R. The heritability of glaucoma-related traits corneal hysteresis, central corneal thickness, intraocular pressure, and choroidal blood flow pulsatility. PLoS One 8:e55573, 2013.

48. Detry-Morel, M., Jamart, J., Hautenauven, F., and Pourjavan, S. Comparison of the corneal biomechanical properties with the Ocular Response Analyzer(R) (ORA) in African and Caucasian normal subjects and patients with glaucoma. Acta Ophthalmol. 90:e118-e124, 2012.

49. Lim, L., Gazzard, G., Chan, Y.H., et al. Cornea biomechanical characteristics and their correlates with refractive error in Singaporean children. Invest. Ophthalmol. Vis. Sci. 49:3852-3857, 2008.

50. Foster, P.J., Broadway, D.C., Garway-Heath, D.F., et al. Intraocular pressure and corneal biomechanics in an adult British population: the EPIC-Norfolk eye study. Invest. Ophthalmol. Vis. Sci. 52:8179-8185, 2011.

51. Ortiz, D., Pinero, D., Shabayek, M.H., Arnalich-Montiel, F., and Alio, J.L. Corneal biomechanical properties in normal, post-laser in situ keratomileusis, and keratoconic eyes. J. Cataract Refract. Surg. 33:1371-1375, 2007.

52. Schweitzer, C., Korobelnik, J.F., Boniol, M., et al. Associations of biomechanical properties of the cornea with environmental and metabolic factors in an elderly population: the ALIENOR Study. Invest. Ophthalmol. Vis. Sci. 57:2003-2011, 2016.

53. Kaushik, S., Pandav, S.S., Banger, A., Aggarwal, K., and Gupta, A. Relationship between corneal biomechanical properties, central corneal thickness, and intraocular pressure across the spectrum of glaucoma. Am. J. Ophthalmol. 153:840.e2-849.e2, 2012.

54. Narayanaswamy, A., Chung, R.S., Wu, R.Y., et al. Determinants of corneal biomechanical properties in an adult Chinese population. Ophthalmology 118:12531259, 2011.

55. Kamiya, K., Hagishima, M., Fujimura, F., and Shimizu, K. Factors affecting corneal hysteresis in normal eyes. Graefes Arch. Clin. Exp. Ophthalmol. 246:1491-1494, 2008.

56. Broman, A.T., Congdon, N.G., Bandeen-Roche, K., and Quigley, H.A. Influence of corneal structure, corneal responsiveness, and other ocular parameters on tonometric measurement of intraocular pressure. J. Glaucoma 16: 581-588, 2007.

57. Kotecha, A., Elsheikh, A., Roberts, C.R., Zhu, H., and Garway-Heath, D.F. Corneal thickness- and age-related biomechanical properties of the cornea measured with the ocular response analyzer. Invest. Ophthalmol. Vis. Sci. 47: 5337-5347, 2006.

58. Pillunat, K.R., Hermann, C., Spoerl, E., and Pillunat, L.E. Analyzing biomechanical parameters of the cornea with 
glaucoma severity in open-angle glaucoma. Graefes Arch. Clin. Exp. Ophthalmol. 254:1345-1351, 2016.

59. Park, J.H., Jun, R.M., and Choi, K.R. Significance of corneal biomechanical properties in patients with progressive normal-tension glaucoma. Br. J. Ophthalmol. 99: 746-751, 2015.

60. Ayala, M. Corneal hysteresis in normal subjects and in patients with primary open-angle glaucoma and pseudoexfoliation glaucoma. Ophthalmic Res. 46:187-191, 2011.

61. Beyazyildiz, E., Beyazyildiz, O., Arifoglu, H.B., Altintas, A.K., and Koklu, S.G. Comparison of ocular response analyzer parameters in primary open angle glaucoma and exfoliative glaucoma patients. Indian J. Ophthalmol. 62: 782-787, 2014.

62. Yazgan, S., Celik, U., Alagoz, N., and Tas, M. Corneal biomechanical comparison of pseudoexfoliation syndrome, pseudoexfoliative glaucoma and healthy subjects. Curr. Eye Res. 40:470-475, 2015.

63. Cankaya, A.B., Anayol, A., Ozcelik, D., Demirdogen, E., and Yilmazbas, P. Ocular response analyzer to assess corneal biomechanical properties in exfoliation syndrome and exfoliative glaucoma. Graefes Arch. Clin. Exp. Ophthalmol. 250:255-260, 2012.

64. Sbeity, Z., Palmiero, P.M., Tello, C., Liebmann, J.M., and Ritch, R. Non-contact in vivo confocal scanning laser microscopy in exfoliation syndrome, exfoliation syndrome suspect and normal eyes. Acta Ophthalmol. 89: 241-247, 2011.

65. Congdon, N.G., Broman, A.T., Bandeen-Roche, K., Grover, D., and Quigley, H.A. Central corneal thickness and corneal hysteresis associated with glaucoma damage. Am. J. Ophthalmol. 141:868-875, 2006.

66. De Moraes, C.V., Hill, V., Tello, C., Liebmann, J.M., and Ritch, R. Lower corneal hysteresis is associated with more rapid glaucomatous visual field progression. J. Glaucoma 21:209-213, 2012.

67. Medeiros, F.A., Meira-Freitas, D., Lisboa, R., Kuang, T.M., Zangwill, L.M., and Weinreb, R.N. Corneal hysteresis as a risk factor for glaucoma progression: a prospective longitudinal study. Ophthalmology 120:15331540, 2013.

68. Hong, Y., Shoji, N., Morita, T., et al. Comparison of corneal biomechanical properties in normal tension glaucoma patients with different visual field progression speed. Int. J. Ophthalmol. 9:973-978, 2016.

69. Chee, R.I., Silva, F.Q., Ehrlich, J.R., and Radcliffe, N.M. Agreement of flicker chronoscopy for structural glaucomatous progression detection and factors associated with progression. Am. J. Ophthalmol. 155:983.e1-990.e1, 2013.

70. Khawaja, A.P., Chan, M.P., Broadway, D.C., et al. Corneal biomechanical properties and glaucoma-related quantitative traits in the EPIC-Norfolk Eye Study. Invest Ophthalmol. Vis Sci. 55:117-124, 2014.

71. Frantz, C., Stewart, K.M., and Weaver, V.M. The extracellular matrix at a glance. J. Cell. Sci. 123:4195-4200, 2010.

72. Mithieux, S.M., and Weiss, A.S. Elastin. Adv. Protein Chem. 70:437-461, 2005.

73. Wagenseil, J.E., and Mecham, R.P. Elastin in large artery stiffness and hypertension. J. Cardiovasc. Transl. Res. 5: 264-273, 2012.

74. Edeleva, E.V., and Shcherbata, H.R. Stress-induced ECM alteration modulates cellular microRNAs that feedback to readjust the extracellular environment and cell behavior. Front. Genet. 4:305, 2013.
75. Humphrey, J.D., and Rajagopal, K.R. A constrained mixture model for growth and remodeling of soft tissues. Math. Mod. Methods Appl. Sci. 12: 407-430, 2002.

76. Valentin, A., and Humphrey, J.D. Evaluation of fundamental hypotheses underlying constrained mixture models of arterial growth and remodelling. Philos. Trans. A Math. Phys. Eng. Sci. 367:3585-3606, 2009.

77. Abraham, D.J., Eckes, B., Rajkumar, V., and Krieg, T. New developments in fibroblast and myofibroblast biology: implications for fibrosis and scleroderma. Curr. Rheumatol. Rep. 9:136-143, 2007.

78. Kass, L., Erler, J.T., Dembo, M., and Weaver, V.M. Mammary epithelial cell: influence of extracellular matrix composition and organization during development and tumorigenesis. Int. J. Biochem. Cell Biol. 39:1987-1994, 2007.

79. Butcher, D.T., Alliston, T., and Weaver, V.M. A tense situation: forcing tumour progression. Nat. Rev. Cancer 9: 108-122, 2009.

80. Provenzano, P.P., Inman, D.R., Eliceiri, K.W., et al. Collagen density promotes mammary tumor initiation and progression. BMC Med. 6:11, 2008.

81. Erler, J.T., and Weaver, V.M. Three-dimensional context regulation of metastasis. Clin. Exp. Metastasis 26:35-49, 2009.

82. Kirschmann, D.A., Seftor, E.A., Fong, S.F., et al. A molecular role for lysyl oxidase in breast cancer invasion. Cancer Res. 62:4478-4483, 2002.

83. Barker, H.E., Chang, J., Cox, T.R., et al. LOXL2mediated matrix remodeling in metastasis and mammary gland involution. Cancer Res. 71:1561-1572, 2011.

84. Olsen, K.C., Epa, A.P., Kulkarni, A.A., et al. Inhibition of transglutaminase 2, a novel target for pulmonary fibrosis, by two small electrophilic molecules. Am. J. Respir. Cell Mol. Biol. 50:737-747, 2014.

85. Nurminskaya, M.V., and Belkin, A.M. Cellular functions of tissue transglutaminase. Int. Rev. Cell Mol. Biol. 294: 1-97, 2012.

86. Chen, J.S., and Mehta, K. Tissue transglutaminase: an enzyme with a split personality. Int. J. Biochem. Cell Biol. 31:817-836, 1999.

87. Olsen, K.C., Sapinoro, R.E., Kottmann, R.M., et al. Transglutaminase 2 and its role in pulmonary fibrosis. Am. J. Respir. Crit. Care Med. 184:699-707, 2011.

88. Grenard, P., Bresson-Hadni, S., El Alaoui, S., Chevallier, M., Vuitton, D.A., and Ricard-Blum, S. Transglutaminasemediated cross-linking is involved in the stabilization of extracellular matrix in human liver fibrosis. J. Hepatol. 35: 367-375, 2001.

89. Lin, C.H., Chen, J., Zhang, Z., et al. Endostatin and transglutaminase 2 are involved in fibrosis of the aging kidney. Kidney Int. 89:1281-1292, 2016.

90. Kumar, A., Hu, J., LaVoie, H.A., Walsh, K.B., DiPette, D.J., and Singh, U.S. Conformational changes and translocation of tissue-transglutaminase to the plasma membranes: role in cancer cell migration. BMC Cancer 14:256, 2014.

91. Nowotny, K., Jung, T., Hohn, A., Weber, D., and Grune, T. Advanced glycation end products and oxidative stress in type 2 diabetes mellitus. Biomolecules 5:194-222, 2015.

92. Tezel, G. Oxidative stress in glaucomatous neurodegeneration: mechanisms and consequences. Prog. Retin. Eye Res. 25:490-513, 2006.

93. Liu, B., McNally, S., Kilpatrick, J.I., Jarvis, S.P., and O'Brien, C.J. Aging and ocular tissue stiffness in glaucoma. Surv. Ophthalmol. 63:56-74, 2018. 
94. Lanzagorta-Aresti, A., Perez-Lopez, M., Palacios-Pozo, E., and Davo-Cabrera, J. Relationship between corneal hysteresis and lamina cribrosa displacement after medical reduction of intraocular pressure. Br. J. Ophthalmol. 101: 290-294, 2017.

95. Albon, J., Karwatowski, W.S., Easty, D.L., Sims, T.J., and Duance, V.C. Age related changes in the non-collagenous components of the extracellular matrix of the human lamina cribrosa. Br. J. Ophthalmol. 84:311-317, 2000.

96. Albon, J., Purslow, P.P., Karwatowski, W.S., and Easty, D.L. Age related compliance of the lamina cribrosa in human eyes. Br. J. Ophthalmol. 84:318-323, 2000.

97. Wordinger, R.J., and Clark, A.F. Lysyl oxidases in the trabecular meshwork. J. Glaucoma 23(Suppl 1):S55-S58, 2014.

98. Last, J.A., Pan, T., Ding, Y., et al. Elastic modulus determination of normal and glaucomatous human trabecular meshwork. Invest. Ophthalmol. Vis. Sci. 52:21472152, 2011.

99. Daxer, A., Misof, K., Grabner, B., Ettl, A., and Fratzl, P. Collagen fibrils in the human corneal stroma: structure and aging. Invest. Ophthalmol. Vis. Sci. 39:644-648, 1998.

100. Malik, N.S., Moss, S.J., Ahmed, N., Furth, A.J., Wall, R.S., and Meek, K.M. Ageing of the human corneal stroma: structural and biochemical changes. Biochim. Biophys. Acta 1138:222-228, 1992.

101. Smith-Mungo, L.I., and Kagan, H.M. Lysyl oxidase: properties, regulation and multiple functions in biology. Matrix Biol. 16:387-398, 1998.

102. Liu, X., Zhao, Y., Gao, J., et al. Elastic fiber homeostasis requires lysyl oxidase-like 1 protein. Nat. Genet. 36:178$182,2004$.

103. Moon, H.J., Finney, J., Ronnebaum, T., and Mure, M. Human lysyl oxidase-like 2. Bioorg. Chem. 57:231-241, 2014.

104. Thorleifsson, G., Magnusson, K.P., Sulem, P., et al. Common sequence variants in the LOXL1 gene confer susceptibility to exfoliation glaucoma. Science 317:13971400, 2007.

105. Schlotzer-Schrehardt, U. Molecular pathology of pseudoexfoliation syndrome/glaucoma-new insights from LOXL1 gene associations. Exp. Eye Res. 88:776-785, 2009.

106. Schlotzer-Schrehardt, U., Hammer, C.M., Krysta, A.W., et al. LOXL1 deficiency in the lamina cribrosa as candidate susceptibility factor for a pseudoexfoliation-specific risk of glaucoma. Ophthalmology 119:1832-1843, 2012.

107. Sethi, A., Mao, W., Wordinger, R.J., and Clark, A.F. Transforming growth factor-beta induces extracellular matrix protein cross-linking lysyl oxidase (LOX) genes in human trabecular meshwork cells. Invest. Ophthalmol. Vis. Sci. 52:5240-5250, 2011.

108. Schlotzer-Schrehardt, U., Pasutto, F., Sommer, P., et al. Genotype-correlated expression of lysyl oxidase-like 1 in ocular tissues of patients with pseudoexfoliation syndrome/glaucoma and normal patients. Am. J. Pathol. 173: 1724-1735, 2008.

109. Chen, H., Chen, L.J., Zhang, M., et al. Ethnicity-based subgroup meta-analysis of the association of LOXL1 polymorphisms with glaucoma. Mol. Vis. 16:167-177, 2010.

110. Sun, W., Sheng, Y., Weng, Y., et al. Lack of association between lysyl oxidase-like 1 polymorphisms and primary open angle glaucoma: a meta-analysis. Int. J. Ophthalmol. 7:550-556, 2014.
111. Wu, M., Zhu, X.Y., and Ye, J. Associations of polymorphisms of LOXL1 gene with primary open-angle glaucoma: a meta-analysis based on 5,293 subjects. Mol. Vis. 21:165-172, 2015.

112. Shiga, Y., Akiyama, M., Nishiguchi, K.M., et al. Genomewide association study identifies seven novel susceptibility loci for primary open-angle glaucoma. Hum. Mol. Genet. 27:1486-1496, 2018.

113. Belkin, A.M. Extracellular TG2: emerging functions and regulation. FEBS J. 278:4704-4716, 2011.

114. Tovar-Vidales, T., Clark, A.F., and Wordinger, R.J. Focus on molecules: transglutaminase 2. Exp. Eye Res. 93:2-3, 2011.

115. Tovar-Vidales, T., Roque, R., Clark, A.F., and Wordinger, R.J. Tissue transglutaminase expression and activity in normal and glaucomatous human trabecular meshwork cells and tissues. Invest. Ophthalmol. Vis. Sci. 49:622628, 2008.

116. Zeimer, R.C., and Ogura, Y. The relation between glaucomatous damage and optic nerve head mechanical compliance. Arch. Ophthalmol. 107:1232-1234, 1989.

117. Tengroth, B., and Ammitzboll, T. Changes in the content and composition of collagen in the glaucomatous eyebasis for a new hypothesis for the genesis of chronic open angle glaucoma - a preliminary report. Acta Ophthalmol. (Copenh). 62:999-1008, 1984.

118. Burgoyne, C.F., Downs, J.C., Bellezza, A.J., Suh, J.K., and Hart, R.T. The optic nerve head as a biomechanical structure: a new paradigm for understanding the role of IOP-related stress and strain in the pathophysiology of glaucomatous optic nerve head damage. Prog. Retin. Eye Res. 24:39-73, 2005.

119. Hernandez, M.R., Andrzejewska, W.M., and Neufeld, A.H. Changes in the extracellular matrix of the human optic nerve head in primary open-angle glaucoma. Am. J. Ophthalmol. 109:180-188, 1990.

120. Irnaten, M., Rahman, N., and O'Brien, C. The mRNA expression of TG-2 and LOX-1 in normal versus glaucoma LC cells. Dublin: Mater Misericordiae University Hospital; 2017.

121. Kandarakis, S.A., Piperi, C., Topouzis, F., and Papavassiliou, A.G. Emerging role of advanced glycation-end products (AGEs) in the pathobiology of eye diseases. Prog. Retin. Eye Res. 42:85-102, 2014.

122. Kaji, Y., Amano, S., Usui, T., et al. Expression and function of receptors for advanced glycation end products in bovine corneal endothelial cells. Invest. Ophthalmol. Vis. Sci. 44:521-528, 2003.

123. Sady, C., Khosrof, S., and Nagaraj, R. Advanced Maillard reaction and crosslinking of corneal collagen in diabetes. Biochem. Biophys. Res. Commun. 214:793-797, 1995.

124. Kanai, A., and Kaufman, H.E. Electron microscopic studies of corneal stroma: aging changes of collagen fibers. Ann. Ophthalmol. 5:285-287 passim, 1973.

125. Terai, N., Spoerl, E., Haustein, M., Hornykewycz, K., Haentzschel, J., and Pillunat, L.E. Diabetes mellitus affects biomechanical properties of the optic nerve head in the rat. Ophthalmic Res. 47:189-194, 2012.

126. Tezel, G., Yang, X., and Cai, J. Proteomic identification of oxidatively modified retinal proteins in a chronic pressureinduced rat model of glaucoma. Invest. Ophthalmol. Vis. Sci. 46:3177-3187, 2005.

127. Hondur, G., Goktas, E., Yang, X., et al. Oxidative stressrelated molecular biomarker candidates for glaucoma. Invest. Ophthalmol. Vis. Sci. 58:4078-4088, 2017. 
128. Spoerl, E., Boehm, A.G., and Pillunat, L.E. The influence of various substances on the biomechanical behavior of lamina cribrosa and peripapillary sclera. Invest. Ophthalmol. Vis. Sci. 46:1286-1290, 2005.

129. Barry-Hamilton, V., Spangler, R., Marshall, D., et al. Allosteric inhibition of lysyl oxidase-like-2 impedes the development of a pathologic microenvironment. Nat. Med. 16:1009-1017, 2010.

130. Kothapalli, D., Liu, S.L., Bae, Y.H., et al. Cardiovascular protection by ApoE and ApoE-HDL linked to suppression of ECM gene expression and arterial stiffening. Cell. Rep. 2:1259-1271, 2012.

131. Bordeleau, F., Mason, B.N., Lollis, E.M., et al. Matrix stiffening promotes a tumor vasculature phenotype. Proc. Natl. Acad. Sci. U. S. A. 114:492-497, 2017.

132. Liu, S.B., Ikenaga, N., Peng, Z.W., et al. Lysyl oxidase activity contributes to collagen stabilization during liver fibrosis progression and limits spontaneous fibrosis reversal in mice. FASEB J. 30:1599-1609, 2016.

133. Yang, Y.F., Sun, Y.Y., Acott, T.S., and Keller, K.E. Effects of induction and inhibition of matrix cross-linking on remodeling of the aqueous outflow resistance by ocular trabecular meshwork cells. Sci. Rep. 6:30505, 2016.

134. Kim, S.Y. New insights into development of transglutaminase 2 inhibitors as pharmaceutical lead compounds. Med. Sci. (Basel) 6:87, 2018.

135. Raychaudhuri, U., Millar, J.C., and Clark, A.F. Knockout of tissue transglutaminase ameliorates TGFbeta2-induced ocular hypertension: a novel therapeutic target for glaucoma? Exp. Eye Res. 171:106-110, 2018.

136. Kass, D.A., Shapiro, E.P., Kawaguchi, M., et al. Improved arterial compliance by a novel advanced glycation endproduct crosslink breaker. Circulation 104:1464-1470, 2001.

137. Fujimoto, N., Hastings, J.L., Carrick-Ranson, G., et al. Cardiovascular effects of 1 year of alagebrium and endurance exercise training in healthy older individuals. Circ. Heart Fail. 6:1155-1164, 2013.

138. Kiland, J.A., Gabelt, B.T., Tezel, G., Lutjen-Drecoll, E., and Kaufman, P.L. Effect of the age cross-link breaker alagebrium on anterior segment physiology, morphology, and ocular age and rage. Trans. Am. Ophthalmol. Soc. 107:146-158, 2009.

Received: October 12, 2019 Accepted: May 11, 2020

Address correspondence to: Dr. Najiha Rahman UCD Department of Ophthalmology Mater Misericordiae University Hospital 60 Eccles Street Dublin 7 Ireland

E-mail: najiha.rahman@nhs.net 